\title{
Amyloid Goiter: Clinicopathological Assessment of Two Cases and Review of Literature
}

\author{
Rabab Ahmed Ahmed Mohammed1,2, Etemad Helmy Yassin1, \\ Moustafa EzEldien M. Radwan ${ }^{3,4^{*}}$, Badawy Mohammed Ahmed5, \\ Lobna F. Ettouny', Alaa M. Abozied ${ }^{6}$ \\ ${ }^{1}$ Department of Pathology, Faculty of Medicine, Taibah University, Medina, KSA \\ ${ }^{2}$ Department of Pathology, Faculty of Medicine, Assiut University, Assiut, Egypt \\ ${ }^{3}$ Department of Radiodiagnosis, Faculty of Medicine, Taibah University, Medina, KSA \\ ${ }^{4}$ Department of Radiodiagnosis, Assiut University Hospitals, Assiut, Egypt \\ ${ }^{5}$ Department of Surgical Oncology, South Egypt Cancer Institute, Assiut, Egypt \\ ${ }^{6}$ Department of Internal Medicine, Assiut University Hospitals, Assiut, Egypt \\ Email:
}

Received 2 January 2015; accepted 12 January 2015; published 16 January 2015

Copyright (C) 2015 by authors and Scientific Research Publishing Inc.

This work is licensed under the Creative Commons Attribution International License (CC BY).

http://creativecommons.org/licenses/by/4.0/

c) $\underset{\mathrm{EY}}{\mathrm{B}}$ Open Access

\begin{abstract}
Amyloid goiter (AG) is a rare but well-established disease entity that may occur in a number of conditions. In the following article, we will report two cases of AG. Both patients were young males: $28 \& 24$ years old, presented with rapidly enlarging thyroid gland manifested with pressure effects (dyspnea and hoarseness of voice). Provisional clinical diagnosis was malignant thyroid neoplasm. One of the patients was markedly hypothyroid while the other was euthyroid. Histopathological evaluation revealed extracellular deposition of deep pink homogenous material that was confirmed as amyloid with congo red. Patient in case 1 was primary localized AG while patient in case 2 was systemic amyloidosis secondary to interstitial pulmonary fibrosis (IPF) that was first manifested by AG. The main aims of the article were to describe histopathological features of amyloidosis of the thyroid gland and to raise awareness of AG to be included in the differential diagnosis in patients presented with rapidly enlarging goiter with mass effects.
\end{abstract}

\section{Keywords}

Amyloidosis, Amyloid Goiter, Thyroid Gland

${ }^{*}$ Corresponding author.

How to cite this paper: Mohammed, R.A.A., Yassin, E.H., Radwan, M.E.M., Ahmed, B.M., Ettouny, L.F. and Abozied, A.M. (2015) Amyloid Goiter: Clinicopathological Assessment of Two Cases and Review of Literature. Open Journal of Pathology, 5, 20-27. http://dx.doi.org/10.4236/ojpathology.2015.51004 


\section{Introduction}

Amyloid goiter (AG) is thyroid enlargement caused by deposition of amyloid protein. Although a rare condition, AG is a well-established disease entity that was first described by Rockitansky in 1855 followed by several description of the condition in literature [1].

Deposition of amyloid in the thyroid gland may occur in a number of different disease conditions. It occurs in about $50 \%$ to $70 \%$ of medullary thyroid carcinoma, secondary to long standing inflammatory conditions such as rheumatoid arthritis [2], cystic fibrosis [3] [4], ankylosing sponilitis [5] and Crohn's disease [6]. AG may also be secondary to long standing chronic infectious inflammatory diseases such as bronchiectasis [7] and tuberculosis [8]. The condition was reported in association with renal failure [9], nephritic syndrome [10] and familial Mediterranean fever (FMF) [11]. In autopsy specimen examination, AG was reported in $80 \%$ of patients with secondary amyloidosis and in $50 \%$ of patients with primary amyloidosis [1].

Patients with AG vary in their clinical presentation and symptoms. In cases of primary AG with no significant thyroid enlargement or systemic affection, the patient is usually asymptomatic. However sometime later, many of those patients present rapidly enlarging goiter causing mass effects such as dyspnea, stridor, hoarseness of voice and dysphagia. This presentation raises high susceptibility for thyroid malignancy and therefore usually diagnosed clinically as malignant lymphomas or anaplastic carcinoma particularly in elderly patients. It was reported that majority of patients with AG did have euthyroid function however few might have hypo [12] or hyper thyroidism [13] [14].

According to the degree of thyroid enlargement the WHO recommended a staging system for AG that ranges from stage 0 to III. stage 0 (no apparent goiter), stage IA (palpable goiter but not clinically apparent), Stage IB (palpable clinically apparent in fully extended neck) and stage II (apparent on resting normally-positioned neck) and stage III very large goiter that is obviously apparent [15].

In the following article we describe two cases of stage III AG, the first case is primary organ-isolated AG while the second case is AG secondary to interstitial pulmonary fibrosis (IPF) with possible systematic affection.

\section{Material and Methods}

- Each patient was examined clinically for determination of degree of goiter, and signs of other systematic affection. Patients' consents were taken for reporting their cases.

- Laboratory investigations were conducted (Complete blood picture count using CELL-DYN 3700, thyroid function tests using Immulit-1000, liver function tests, renal function tests using Hitachi Modular, and urine analysis was manually conducted) data were collected for each patient.

- Each patient was subjected to imaging assessment (chest X-ray, US and CT neck, chest and abdomen).

- After surgical removal of the thyroid gland, specimens from both patients were fixed in formalin and processed to formalin fixed paraffin-embedded blocks as used in conventional histopathology labs.

- A representative section from each specimen was stained with hematoxyline and eosin and with Congo red stain.

- Review of PubMed data base was done using the key word "Amyloid goiter”.

\section{Results}

\subsection{Case 1}

A 24 years old male patient presented to surgical oncology clinic complaining of dyspnea and respiratory distress with rapidly progressively enlarged thyroid. The patient gave a long history of generalized easy fatigability and wasting which raised possibility of GIT malignancy and patient was therefore subjected to upper and lower endoscopy, however both were free. On presentation, the clinical examination revealed bilateral diffuse enlargement of the thyroid gland associated with hoarseness of voice. Provisional clinical diagnosis was Hashimoto's thyroiditis or thyroid malignant lymphoma.

Imaging studies using neck US showed diffuse, heterogenous thyroid swelling with bilateral enlarged cervical lymph nodes with reactive features. Abdominal sonar was free. No abnormal features in spleen, liver, adrenals, kidneys, pancreas or abdominal LNs were detected. Laboratory investigations (thyroid function test) revealed marked hypothyroidism, normal range for liver functions, normal range for renal function tests and mild in- 
crease in neutrophil on complete blood count. Detailed lab findings are summarized in Table 1. Gross histopathological examination revealed diffuse bilateral enlargement of the thyroid gland measuring $8 \times 4 \times 3$ and $7 \times 4$ $\times 3 \mathrm{~cm}$. the outer surface was smooth in most parts with mild nodularity due to presence of cystic changes. Upon cutting the cut section appeared glistening with a mixture of grayish white and yellowish areas (Figures 1(A)-(C)). Microscopic examination revealed wide spread diffuse replacement of the thyroid follicles with extracellular eosinophilic structurless homogenous material that was diagnosed as amyloidosis of the thyroid gland (Figure 2(A), Figure 2(B)). Few scattered remaining thyroid follicles with atrophic lining epithelium were detected (Figure 2(B)). Few aggregates of adipocytes in the form of lobules were seen. Among the amyloid deposit there were areas of chronic inflammatory cell infiltrate with numerous foreign-body giant cell formation (Figure 1). Congo red staining revealed dark orange coloration of the deposited eosinophilic material which confirmed the amyloid nature of the deposit (Figure 2(D)).

The case is not associated with immuno-proliferative, chronic diseases or any other system affection, therefore was considered primary localized amyloidosis in the thyroid gland. The patient was operated for total thyroidectomy with preservation of recurrent and superior laryngeal nerves and parathyroid glands. The operation wasdone to relief respiratory distress and to obtain tissue for pathological diagnosis. Postoperative hormonal

Table 1. Laboratory findings from patients in case 1 and case 2.

\begin{tabular}{|c|c|c|}
\hline & AG case 1 test value (normal range) & AG case 2 test value (normal range) \\
\hline \multicolumn{3}{|c|}{ Thyroid function analysis } \\
\hline $\mathrm{TSH}$ & $100.1 \mathrm{uIU} / \mathrm{ml}(0.84-1.72)$ & $2.6(0.4-6.2) \mathrm{ml} \mathrm{U} / \mathrm{L}$ \\
\hline T3 & $0.8 \mathrm{ng} / \mathrm{ml}(4.5-12.5)$ & $2.1(0.96-2.02) \mathrm{ng} / \mathrm{ml}$ \\
\hline $\mathrm{T} 4$ & $0.01 \mathrm{ng} / \mathrm{ml}(0.36-4.7)$ & $12(4.8-12.00 \mathrm{ug} / \mathrm{dl}$ \\
\hline Calcitonin & Not measured & 6.0 (uo to $13 \mathrm{pg} / \mathrm{dl}$ ) \\
\hline Hb concentration & $10.5 \mathrm{~g} / \mathrm{dl}(13-18)$ & $8.4 \mathrm{~g} / \mathrm{dl}(13-18)$ \\
\hline \multicolumn{3}{|c|}{ Urine analysis } \\
\hline Color & Clear yellow & Turbid acidic urine \\
\hline Pus cells & $1-2$ & $15-18$ \\
\hline Albumin & Absent & Albumin ++ \\
\hline Casts & Absent & Casts +++ \\
\hline RBC & $2-3$ & RBC $6-8$ \\
\hline Bile and bilirubin & Nil & Normal \\
\hline Crystals & Nil & +Ca oxalate \\
\hline \multicolumn{3}{|c|}{ Liver enzymes } \\
\hline S.G.O.T & $12.6 \mathrm{mg} / \mathrm{dl}$ (up to 45 u.D) & $19.9 \mathrm{mg} / \mathrm{dl}$ (up to 45 u.D) \\
\hline S.G.P.T & $14.8 \mathrm{mg} / \mathrm{dl}$ (up to 40 u.D) & $25.5 \mathrm{mg} / \mathrm{dl}$ (up to $40 \mathrm{u} . \mathrm{D}$ ) \\
\hline \multicolumn{3}{|c|}{ Renal functions } \\
\hline Blood urea & $28 \mathrm{mg} / \mathrm{dl}(15-45)$ & $34 \mathrm{mg} / \mathrm{dl}(15$ - 45) \\
\hline Serum ceriatinin & $0.8(0.5-1.36 \mathrm{mag} / \mathrm{dl})$ & $0.5(0.5-1.36 \mathrm{mag} / \mathrm{dl})$ \\
\hline \multicolumn{3}{|c|}{ Coagulation assay } \\
\hline Prothrombin time & 15 seconds & 14.8 second \\
\hline Prothrombin concentration & $79 \%$ & $73 \%$ \\
\hline Adrenal function profile & Not measured & VMA 24 h urine 3.8 (0 - 13.6 mg/day) \\
\hline
\end{tabular}




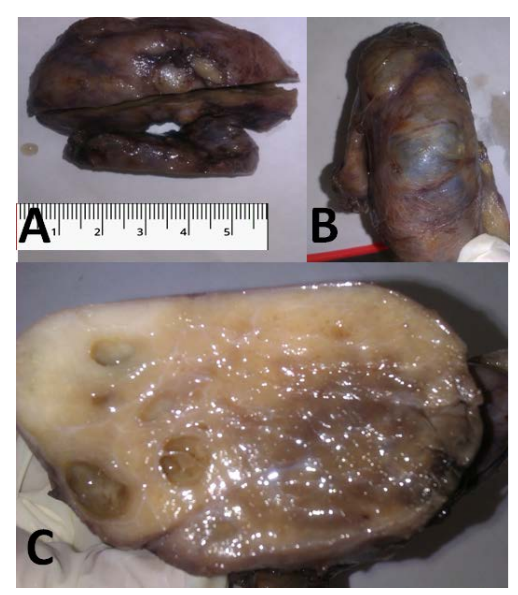

Figure 1. Gross features of amyloid goiter. First and second panels are from patient in case 1. (A) Gross features of the Rt lobe of the removed thyroid gland showing enlargement with mild nodularity of the surface; (B) Areas of cystic degeneration are seen as bluish colored domed cysts; (C) The cut surface appeared grayish white with yellowish areas and cystic changes.

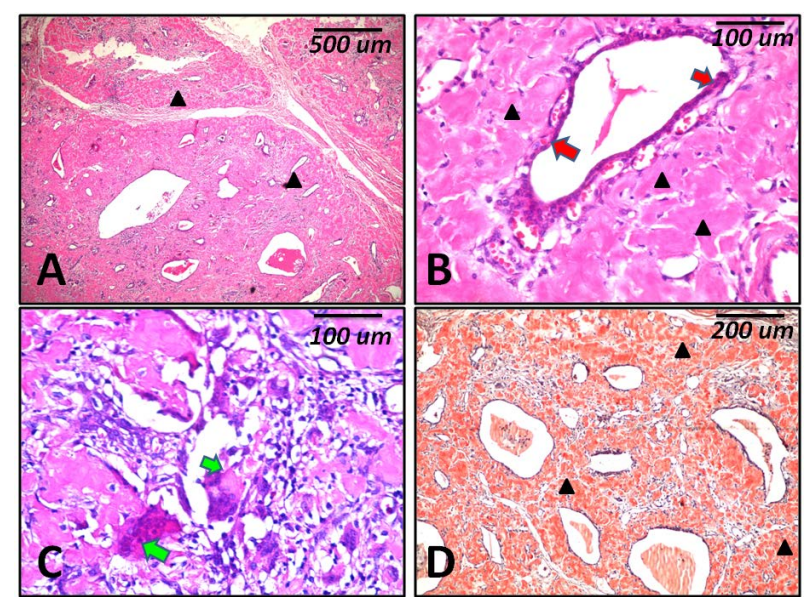

Figure 2. Histopathological features (case 1). (A) to (D) are microscopic features of the case 1 showing diffuse eosinophilic homogenous material deposits (black arrow heads) ((A) $\times 40)$, Few scattered remaining thyroid follicles with atrophic lining epithelium (red arrows) ((B) $\times 200)$ and areas of chronic inflammatory cell infiltrate with numerous foreign-body giant cell formation (green arrows) $((C) \times 200)$. Congo red staining shows deep red coloration of the deposits $((\mathrm{D}) \times 100)$. Scale bars indicate magnification in micrometers (um).

replacement treatment was given for the patient with ensuring follow-up for early identification of any further organ affection or development of malignancies.

\subsection{Case 2}

28 years old male patient presented to clinic complaining of rapidly growing neck mass that resulted in shortness of breath for one month duration followed by hoarseness of voice. The patient gave a history of intermittent at- 
tacks of dry cough over the recent few years. Clinical examination revealed normal blood pressure, pulse rate and temperature. Neck examination revealed enlarged thyroid gland with retrosternal extension (without raise in the jugular venous pressure) and small cervical enlarged lymph node. Chest examination revealed bilateral basal dry crepitation with occasional rhonchi. Cardiac, abdominal, neurological clinical examinations were free.

Chest imaging: X-ray showed reticulonodular pulmonary shadows that confirmed by chest CT as interstitial pulmonary fibrosis. No enlarged hilar LNs were detected. Neck imaging: US showed bilateral nodular enlargement of both lobes of the thyroid gland and one enlarged cervical LN. Multislice computed tomography (MSCT) showed the same picture. The enlarged node showed reactive features. Abdominal US and CT revealed ectopic malrotated Rt kidney in the Rt lumbar region. Lt kidney is normal. No changes in the spleen, LNs and other organs and no asitic collection. The patient has no history of environmental exposure to agents that known to cause IPF or certain drug intake. No history or clinical/laboratory evidences for connective tissue diseases. Laboratory investigations (thyroid function test) revealed euthyroid state, Liver and renal function tests did not show abnormal findings. Urine analysis revealed albuminurea with features of presence of crystal depositions with secondary infection. Detailed lab findings are summarized in Table 1. As the case is associated with IPF, it was considered reactive (secondary) AG. Histopathological examination showed features more or less similar to the amyloid goiter in case 1 however was characterized with diffuse fatty infiltration as shown in Figure 3. Detailed lab findings are summarized in Table 1. Because the case is associated with IPF; it was considered reactive (secondary) AG.

\section{Discussion and Review of Literature}

In this report, two adult male patients in the third decade presented clinically with rapidly enlarged thyroid mass causing mass effect (stridor and dyspnea). Both conditions were provisionally diagnosed as malignant thyroid tumour after clinical examination. By reviewing the literature it was found that these symptoms are common clinical presentation in patients with AG [3] [8] [16] [17].

Although most of the case reports indicated that AG rarely affects thyroid functions, some patients do suffer thyroid dysfunction in the form of hypo or hyperthyroidism [18]. In our patient in case 1; thyroid function revealed marked hypothyroidism with positive feedback increase in TSH level. While patient in case 2 was euthyroid. The causes of hypothyroidism in AG are variable. Previous cases of AG with hypothyroidism was

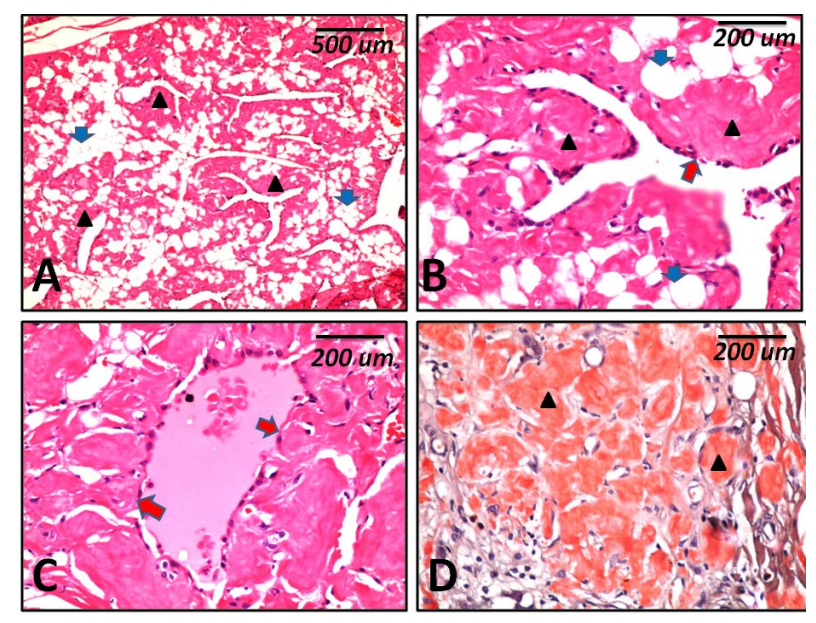

Figure 3. Histopathological features (case 2). (A) to (D) are microscopic features of case 2 showing diffuse eosinophilic homogenous material deposits (black arrow heads) and diffuse fatty infiltration of the thyroid gland (blue arrows) ((A) ×40), Few scattered remaining thyroid follicles with atrophic lining epithelium (red arrows) ((B) $\&(C) \times 200)$. Congo red staining shows deep red coloration of the deposits (arrow heads) $((D) \times 200)$. Scale bars indicate magnification in micrometers (um). 
reported in a case of systemic amyloidosis with amyloid deposition in the pituitary gland [19], associated with cystic fibrosis [4].

In cases associated with subacute thyroiditis and in another case it was found to be due to presence of thyroid autoantibodies [20]. Hypothyroidism in our patient is primarily a thyroid dysfunction not secondary to pituitary hypofunction due to the presence of high TSH levels. Histopathological examination did not show features of thyroiditis. Therefore a possible cause may be due to presence of thyroid autoantibodies; however anti-microsomal and anti-thyroglobulin antibodies were not laboratory tested.

Hisopathological diagnosis of AG is an easy task for experienced pathologists. Identification of histopathological features followed by Congo red staining is the most important tool in diagnosis. However it is the accurate subclassification of amyloidosis into primary versus secondary and single organ versus systemic amyloidosis that is relatively difficult and needs numerous investigations.

Histopathological features in both patients were nearly similar. Both specimens showed wide replacement of the thyroid tissue with the amyloid deposits. The site of deposition was perivascular and parafollicular similar to what was reported in similar reviews [17]. Two histopathological features were different between the two cases; first, in case 1 there were foci of chronic inflammatory cell infiltrate with foreign body giant cell formation; features that were absent in case 2. Second; case 2 was characterized by the presence of extensive lipoid infiltration, while in case 1 lipoid infiltration was only focal and limited. Islands of mature fat in case of AG were suggested to be metaplastic in origin where fat cells are derived from stromal fibroblasts due to chronic tissue hypoxia [21].

Amyloid is a pathologic proteinaceous substance, deposited extracellulary in different organs in a wide variety of diseases. The amyloid protein is composed of two components; fibrillogenic protein (accounts for 95\% of the protein structure) and $\mathrm{P}$ component (accounts for 5\% of protein structure) [22] [23]. It was found that there are 15 types of fibrillogenic component each is unique for each type of amyloidosis and according to which amyloidosis is classified. The most common fibrillogenic types are: 1) AL (amyloid light chain) found in primary amyloidosis is derived from plasma cells and contains immunoglobulin light chains; 2) AA (amyloid-associated) found in secondary amyloidosis is a unique nonimmunoglobulin protein synthesized by the liver from a precursor protein serum amyloid associated (SAA) due to long standing inflammatory conditions; and 3) A $\beta$ amyloid is found in the cerebral lesion of Alzheimer disease [22] [24]. Amyloidosis is divided into a) primary (with no preceding diseases, it accounts for about 30\% of amyloidosis and is usually accompanied with B cell dysfunctions) and b) secondary types (associated with long standing inflammatory disorders or inflammatory conditions as mentioned earlier). Whether primary or secondary, amyloidosis is subdivided into systemic and isolated single organ amyloidosis.

Patient in case 1 did not show any clinical or laboratory evidence for chronic inflammatory conditions or other system affection therefore was diagnosed as primary localized AG. While clinical and laboratory assessment of patient in case 2 showed presence of associated IPF and possible renal affection with amyloidosis (suggested by the presence of excessive protein casts in urine). This indicates a possible systemic secondary form of amyloidosis; however confirmation with histopathological examination of rectal and gingival biopsies and immunohistochemical identification of the deposited amyloid type was not conducted. Amyloidosis was reported previously in cases of IPF [25] however the pathogenesis of AG in association with this condition is not fully understood. In general IPF starts as a reaction to a causative insult or antigen, such as an inhaled environmental organic or inorganic material followed by abnormal immunological response. AG in association with IPF in case 2 is likely to be reactive (secondary) to immunological disorder with systemic affection that first manifested with the rapidly growing goiter.

Both patients were underwent thyroidectomy to alleviate pressure symptoms and were both ensured for follow-up for fear of appearance of malignancies especially plasma cell tumours and lymphoma in case 1 and for fear of deterioration of renal functions in case 2. It is reported that AG may appear before or after the clinical appearance of the overt malignancy and before other system affection [7].

The pathogenesis of secondary systemic amyloidosis is explained by excess production by serum amyloid-associated protein (SAA) that is produced by the liver in long standing inflammatory conditions due to excess stimulation with IL-6 and IL-1. Excess SAA in itself is not enough for development of amyloidosis. Normally SAA is degraded enzymatically (by monocytes-derived enzymes) into soluble components. Only in patients with monocytes enzymatic defects, SAA undergoes incomplete degradation with subsequent abnormal folding and deposition in extracellular tissues [26]. 
The outlook of secondary (reactionary) AA amyloidosis is poor due to high mortality rate due to end-stage renal disease, infection, congestive heart failure, bowel perforation, and gastrointestinal bleeding [17] [27]. Management of AG patients with pressure symptoms is surgical removal. Other important line for management is control of the underlying inflammatory disease. This can lead to stabilization of renal function, reduction in protein excretion, and partial resolution of amyloid deposits. Long-term treatment with colchicine controls the underlying inflammatory disorder, and inhibits secretion of SAA from hepatocytes [28].

Occlusions derived from presentation and discussions of both cases in this report are: a) Although rare, amyoild goiter represents a clinical entity referred to surgical clinic. Because of the unusual worrying presentation, the goiter in those patients is usually diagnosed as malignant tumour; b) Considering AG in mind, diagnosis and rapid adequate management will decrease the duration of morbidity; c) Diagnosis of AG is not just a diagnosis of the amyloid deposit in the gland, two questions must be answered in each case of AG: 1) is it primary or secondary to an underlying condition? 2) Is the thyroid gland the only affected organ? Answering both questions is essential for proper treatment. Immunohistochemical subclassification for the type of the amyloid protein ( $\mathrm{AA}, \mathrm{Al}, \beta \mathrm{A}$, etc.) is helpful in identification of $\mathrm{AG}$ type and therefore for proper treatment of the underlying cause. d) Follow-up of those patients is important because AG is sometime the first manifestation for a following systemic amyloidosis or malignancy.

\section{References}

[1] Villa, F., Dionigi, G., Tanda, M.L., Rovera, F. and Boni, L. (2008) Amyloid Goiter. International Journal of Surgery, 6, S16-S18. http://dx.doi.org/10.1016/j.ijsu.2008.12.025

[2] Duzgun, N., Morris, Y., Yildiz, H.I., Ozturk, S., Ayva, S.K., Ensari, A., et al. (2003) Amyloid Goiter in Juvenile Onset Rheumatoid Arthritis. Scandinavian Journal of Rheumatology, 32, 253-254. http://dx.doi.org/10.1080/03009740310003776

[3] Hamed, G., Heffess, C.S., Shmookler, B.M. and Wenig, B.M. (1995) Amyloid Goiter. A Clinicopathologic Study of 14 Cases and Review of the Literature. American Journal of Clinical Pathology, 104, 306-312.

[4] Alvarez-Sala, R., Prados, C., Sastre Marcos, J., Garcia Rio, F., Vicandi, B., et al. (1995) Amyloid Goitre and Hypothyroidism Secondary to Cystic Fibrosis. Postgraduate Medical Journal, 71, 307-308. http://dx.doi.org/10.1136/pgmj.71.835.307

[5] Cohan, P., Hirschowitz, S., Rao, J.Y., Tanavoli, S. and Van Herle, A.J. (2000) Amyloid Goiter in a Case of Systemic Amyloidosis Secondary to Ankylosing Spondylitis. Journal of Endocrinological Investigation, 23, 762-764.

[6] Habu, S., Watanobe, H., Kimura, K. and Suda, T. (1999) A Case of Amyloid Goiter Secondary to Crohn's Disease. Endocrine Journal, 46, 179-182. http://dx.doi.org/10.1507/endocrj.46.179

[7] Chraibi, A., Msyah, L., Laaribi, O., Marrakchi, A. and Hafidi, A. (2009) Amyloid Goiter: First Sign of Systemic Amyloidosis. Annales d'Endocrinologie, 70, 80-82. http://dx.doi.org/10.1016/j.ando.2007.10.002

[8] D’Antonio, A., Franco, R., Sparano, L., Terzi, G. and Pettinato, G. (2000) Amyloid Goiter: The First Evidence in Secondary Amyloidosis. Report of Five Cases and Review of Literature. Advances in Clinical Pathology, 4, 99-106.

[9] Yildiz, L., Kefeli, M., Kose, B. and Baris, S. (2009) Amyloid Goiter: Two Cases and a Review of the Literature. Annals of Saudi Medicine, 29, 138-141. http://dx.doi.org/10.4103/0256-4947.51808

[10] Bell, G.O. and Mena, B.A. (1963) Amyloid Goiter Associated with the Nephrotic Syndrome. Medical Clinics of North America, 47, 385-389.

[11] Danovitch, G.M., Le Roith, D., Sobel, R., Sikuler, E. and Straus, R. (1979) Amyloid Goitre in Familial Mediterranean Fever. Clinical Endocrinology, 11, 595-601. http://dx.doi.org/10.1111/j.1365-2265.1979.tb03113.x

[12] Kanoh, T., Shimada, H., Uchino, H. and Matsumura, K. (1989) Amyloid Goiter with Hypothyroidism. Archives of Pathology \& Laboratory Medicine, 113, 542-544.

[13] Villamil, C.F., Massimi, G., D’Avella, J. and Cole, S.R. (2000) Amyloid Goiter with Parathyroid Involvement: A Case Report and Review of the Literature. Archives of Pathology \& Laboratory Medicine, 124, 281-283.

[14] Siddiqui, M.A., Gertz, M. and Dean, D. (2007) Amyloid Goiter as a Manifestation of Primary Systemic Amyloidosis. Thyroid, 17, 77-80. http://dx.doi.org/10.1089/thy.2006.0045

[15] Ozdemir, B.H., Akman, B. and Ozdemir, F.N. (2001) Amyloid Goiter in Familial Mediterranean Fever (FMF): A Clinicopathologic Study of 10 Cases. Renal Failure, 23, 659-667. http://dx.doi.org/10.1081/JDI-100107362

[16] Srivastava, A., Baxi, M., Yadav, S., Agarwal, A., Gupta, R.K., Misra, S.K. and Mithal, A. (2001) Juvenile Rheumatoid Arthritis with Amyloid Goiter: Report of a Case with Review of the Literature. Endocrine Pathology, 12, 437-441. 
http://dx.doi.org/10.1385/EP:12:4:437

[17] Arafa, S., Sakr, M., Khedr, M., Khalil, R., Abdel-Baset, H., Moussa, M. and El-Sharaky, M. (2001) Amyloid Goiter: A Diagnostic and Therapeutic Challenge. Egyptian Journal of Surgery, 20, 561-567.

[18] Duhra, P. and Cassar, J. (1990) Thyroid Function Tests in Amyloid Goitre. Postgraduate Medical Journal, 66, 304-306. http://dx.doi.org/10.1136/pgmj.66.774.304

[19] Ozdemir, D., Dagdelen, S., Erbas, T., Sokmensuer, C., Erbas, B. and Cila, A. (2011) Amyloid Goiter and Hypopituitarism in a Patient with Systemic Amyloidosis. Amyloid, 18, 32-34. http://dx.doi.org/10.3109/13506129.2010.545961

[20] Kimura, H., Yamashita, S., Ashizawa, K., Yokoyama, N. and Nagataki, S. (1997) Thyroid Dysfunction in Patients with Amyloid Goitre. Clinical Endocrinology, 46, 769-774. http://dx.doi.org/10.1046/j.1365-2265.1997.1841000.x

[21] Schroder, S. and Bocker, W. (1985) Lipomatous Lesions of the Thyroid Gland: A Review. Applied Pathology, 3, 140149.

[22] Kumar, V., Cotran, R.S. and Robbins, S. (1997) Amyloidosis. In: Basic Pathology, 6th Edition, W.B. Saunders Company, Philadelphia, 126-130.

[23] Kisilevsky, R. and Axelrad, M. (1976) The Pathogenesis of Amyloid Deposition: A New Hypothesis. Medical Hypotheses, 2, 233-237. http://dx.doi.org/10.1016/S0306-9877(76)80002-3

[24] Husby, G. (1980) A Chemical Classification of Amyloid: Correlation with Different Clinical Types of Amyloidosis. Scandinavian Journal of Rheumatology, 9, 60-64. http://dx.doi.org/10.3109/03009748009098131

[25] Sharma, O.P. (2001) Unusual Systemic Disorders Associated with Interstitial Lung Disease. Current Opinion in Pulmonary Medicine, 7, 291-294. http://dx.doi.org/10.1097/00063198-200109000-00007

[26] DiBartola, S.P. and Benson, M.D. (1989) The Pathogenesis of Reactive Systemic Amyloidosis. Journal of Veterinary Internal Medicine, 3, 31-41. http://dx.doi.org/10.1111/j.1939-1676.1989.tb00326.x

[27] Gertz, M.A. and Kyle, R.A. (1991) Secondary Systemic Amyloidosis: Response and Survival in 64 Patients. Medicine, 70, 246-256. http://dx.doi.org/10.1097/00005792-199107000-00002

[28] Migita, K., Yamasaki, S., Shibatomi, K., Ida, H., Kita, M., Kawakami, A. and Eguchi, K. (2001) Impaired Degradation of Serum Amyloid A (SAA) Protein by Cytokine-Stimulated Monocytes. Clinical \& Experimental Immunology, 123, 408-411. http://dx.doi.org/10.1046/j.1365-2249.2001.01472.x 
Scientific Research Publishing (SCIRP) is one of the largest Open Access journal publishers. It is currently publishing more than 200 open access, online, peer-reviewed journals covering a wide range of academic disciplines. SCIRP serves the worldwide academic communities and contributes to the progress and application of science with its publication.

Other selected journals from SCIRP are listed as below. Submit your manuscript to us via either submit@scirp.org or Online Submission Portal.
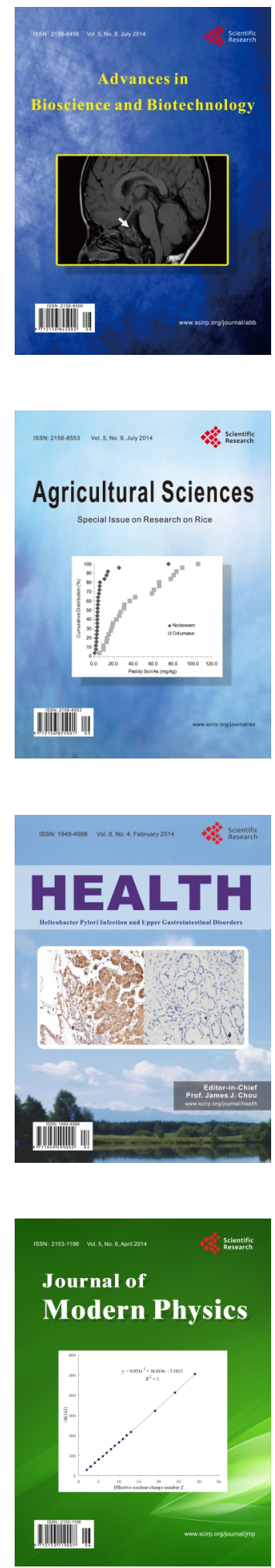
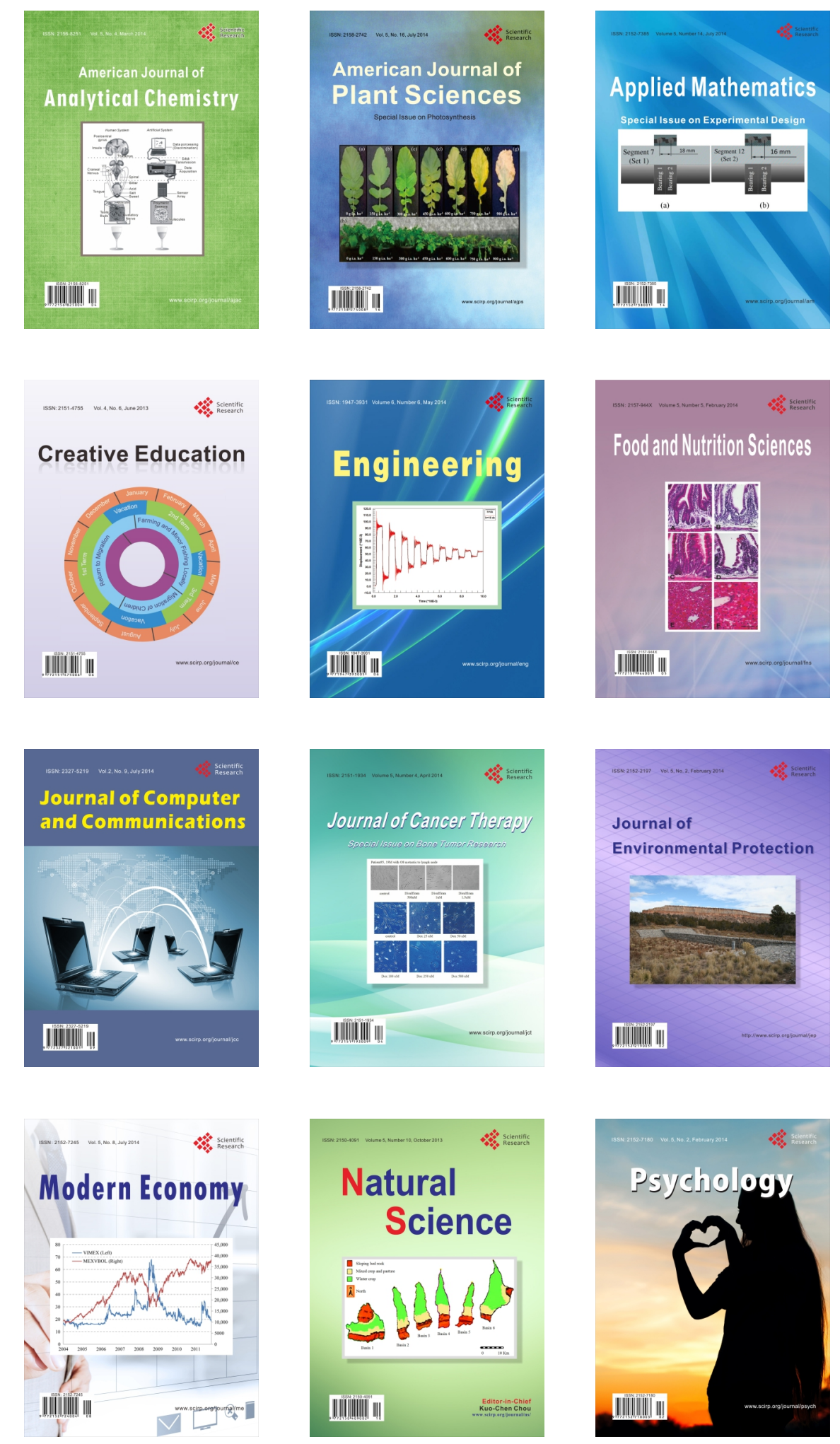